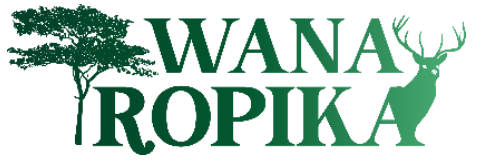

Journal Wanatropika. Vol. 11, No. 2 November 2021

Journal home page: https://jurnal.instiperjogja.ac.id/index.php/JWT/

ISSN: 2088-7019

\title{
UJI EFEKTIVITAS FUNGISIDA NABATI SEBAGAI BAHAN PENGAWET UNTUK MENCEGAH SERANGAN JAMUR PEWARNA KAYU
}

\author{
Effectivity Test of Botanical Fungicide as Preservative \\ to Prevent Wood Staining Fungi Attack \\ Karti Rahayu Kusumaningsih ${ }^{1}$ \\ ${ }^{1}$ Fakultas Kehutanan Institut Pertanian Stiper Yogyakarta, \\ Korespondensi Penulis: wanatropikajurnal@gmail.com
}

\begin{abstract}
Woods which have low natural durability are easy to be attacked with wood staining fungi (blue stain) so can decrease its wood quality. Syzygium aromaticum, Melia azedarach and Piper betle contain of active components (botanical fungicide) that can be used as natural preservative to prevent staining fungi attack. The purpose of this research is to know effect of botanical fungicide species and preserved wood investigated, i.e Paraserianthes falcataria and Toona sureni on the attack intensity of wood staining fungi. Results of the research showed that interaction between botanical fungicide and wood species gived very significant effect on the attack intensity of wood staining fungi. The lowest of attack intensity was resulted on Toona sureni that had preserved by Melia azedarach leaf extract. The leaf extract of Syzygium aromaticum, Melia azedarach and Piper betle could keep Paraserianthes falcataria and Toona sureni wood against staining fungi. Toona sureni wood was more resist against wood staining fungi than Paraserianthes falcataria, it was due to higher extractive in Toona sureni than Paraserianthes falcataria. To preserve woods which had bright colour such as Paraserianthes falcataria, more suitable to use Melia azedarach leaf extract which not change wood colour. Key words: Botanical Fungicide, Preservative, Wood Staining Fungi
\end{abstract}

\section{PENDAHULUAN}

Adanya peningkatan kebutuhan masyarakat akan bahan baku kayu menyebabkan penggunaan jenis-jenis kayu yang memiliki keawetan rendah seperti sengon, meranti, surian, kelapa, dan sebagainya saat ini semakin meningkat. Permasalahan utama dalam penggunaan jenis-jenis kayu dengan keawetan rendah tersebut adalah rentan terhadap serangan berbagai organisme perusak kayu seperti jamur, rayap, dan kumbang bubuk. Jamur pewarna kayu (blue 
stain) merupakan salah satu organisme perusak kayu yang sering menyerang jenis-jenis kayu yang memiliki keawetan rendah. Serangan jamur ini dapat terjadi dalam waktu singkat setelah pohon ditebang atau dalam kondisi segar dengan kadar air lebih dari 30\%, demikian pula pada papan segar yang baru saja digergaji. Akibat serangannya menyebabkan kayu berubah warna menjadi kelabu kebiru-biruan, coklat, bahkan sampai hitam yang disebabkan oleh aktivitas benang-benang hifa jamur yang warnanya relatif gelap. Menurut Schwarze et al. (2000), pewarnaan yang terjadi pada kayu yang terserang jamur pewarna tergantung pada jenis organisme yang menyerang, jenis kayu, serta kadar air kayu. Akibat serangannya menyebabkan kualitas kayu menurun. Kondisi ini akhirnya akan berpengaruh pula terhadap kualitas produk kayu yang dihasilkan, terutama apabila yang dibutuhkan adalah warna alami kayu tersebut. Selain itu kayu yang telah terserang jamur pewarna, pada tingkat lanjut akan terinfeksi pula oleh jamur pembusuk sehingga kerusakan kayu bertambah parah dan pada akhirnya kayu tidak dapat dipergunakan.

Untuk mencegah serangan jamur pewarna pada kayu-kayu dengan keawetan rendah, kayu setelah ditebang harus segera diangkut dari tempat tebangan dan dikeringkan. Namun demikian pengangkutan dan pengeringan kayu seringkali tidak dapat dilakukan secepat mungkin karena beberapa kendala seperti terbatasnya sarana pengangkutan, cuaca buruk (hujan), tempat penimbunan kayu dalam kondisi lembab, tempat pengeringan yang tidak memenuhi persyaratan, dan sebagainya. Oleh karena itu perlu dilakukan pengawetan kayu sebelum kayu tersebut diproses lebih lanjut untuk menghindari serangan jamur pewarna. Pengawetan kayu yang biasanya dilakukan selama ini adalah dengan menggunakan bahan pengawet kimia. Kelemahan bahan pengawet kimia tersebut adalah tidak dapat terurai di alam (non biodegradable) sehingga dapat memberikan dampak negatif terhadap lingkungan dan pemakainya, serta harga bahan pengawet kimia yang relatif mahal. Oleh karena itu perlu digunakan bahan pengawet alternatif yang selain mampu mencegah serangan organisme perusak kayu seperti jamur pewarna, juga relatif aman digunakan, mudah diperoleh, murah, serta mudah diaplikasikan pada kayu.

Jenis-jenis tanaman tertentu seperti cengkeh (Syzygium aromaticum), mindi (Melia azedarach) dan sirih (Piper betle), mengandung bahan aktif (pestisida atau fungisida nabati) yang bersifat racun atau penangkal terhadap hama maupun penyakit pada tanaman. Bahan aktif berupa eugenol pada tanaman cengkeh, azadirachtin pada tanaman mindi, dan fenol pada tanaman sirih, mampu bersifat insektisida maupun fungsida (Prakash dan Rao, 1997). Pestisida atau fungisida nabati tersebut selama ini biasanya digunakan untuk mengendalikan serangan serangga maupun jamur pada tanaman pertanian. Dengan demikian bahan aktif yang 
terkandung dalam jenis-jenis tanaman tersebut dapat diekstrak untuk dibuat menjadi bahan pengawet alami untuk mencegah serangan jamur pewarna kayu (blue stain) yang sering menyerang jenis-jenis kayu dengan keawetan rendah seperti kayu sengon (Paraserianthes falcataria) dan surian (Toona sureni). Kedua jenis kayu tersebut banyak dipakai oleh masyarakat untuk bahan bangunan, mebel dan barang kerajinan. Namun demikian salah satu kendala dalam penggunaan kayu tersebut adalah mudah terserang oleh jamur pewarna, sehingga perlu dilakukan upaya pengawetan sebelum kayu tersebut diproses lebih lanjut dan dipergunakan untuk berbagai keperluan.

Jenis bahan aktif yang terdapat dalam tanaman penghasil fungisida nabati akan menentukan intensitas serangan jamur pewarna yang terjadi pada kayu yang diawetkan. Dengan demikian jenis fungisida nabati yang digunakan sebagai bahan pengawet perlu diuji efektivitasnya agar dapat diaplikasikan pada kayu. Selain itu jenis kayu juga turut menentukan intensitas serangan jamur pewarna. Adanya perbedaan kandungan dan jenis zat ekstraktif yang terdapat di dalam kayu serta didukung oleh perbedaan struktur anatomi, sifat-sifat fisik dan fisika kayu, akan berpengaruh terhadap tinggi rendahnya intensitas serangan jamur pewarna yang terjadi.

Dalam penelitian ini dilakukan pengawetan kayu sengon (Paraserianthes falcataria) dan surian (Toona sureni) dengan menggunakan bahan pengawet yang berasal dari ekstrak serbuk daun cengkeh (Syzygium aromaticum), mindi (Melia azedarach), dan sirih (Piper betle), kemudian dilakukan pengumpanan secara alami terhadap jamur pewarna kayu. Dengan demikian dapat diketahui pengaruh jenis fungisida nabati yang digunakan sebagai bahan pengawet serta jenis kayu yang diawetkan terhadap intensitas serangan jamur pewarna yang terjadi setelah kayu diawetkan.

\section{BAHAN DAN METODE}

Bahan-bahan yang digunakan dalam penelitian ini antara lain daun cengkeh (Syzygium aromaticum), mindi (Melia azedarach) dan sirih (Piper betle), kayu sengon (Paraserianthes falcataria), kayu surian (Toona sureni), alkohol, benzena, dan kertas kalkir. Sedangkan alatalat yang digunakan antara lain gergaji, ayakan, kaliper, timbangan analitik, oven, i, bak pengawet, gelas ukur dan blender.

Rancangan yang digunakan dalam penelitian ini adalah rancangan acak lengkap (Completely Randomized Design) dengan menggunakan 2 faktor perlakuan, yaitu jenis fungisida nabati sebagai bahan pengawet dan jenis kayu yang diawetkan. Kedua faktor tersebut disusun sebagai berikut: 
a. Jenis pestisida nabati, terdiri atas :

1) Kontrol (tanpa pestisida nabati)

2) Ekstrak daun cengkeh (Syzygium aromaticum)

3) Ekstrak daun mindi (Melia azedarch)

4) Ekstrak daun sirih (Piper betle)

b. Jenis kayu yang diawetkan, terdiri atas :

1) Kayu sengon (Paraserianthes falcataria)

2) Kayu surian (Toona sureni)

Dari kedua faktor di atas diperoleh $4 \times 2=8$ kombinasi perlakuan, dengan masing-masing kombinasi perlakuan menggunakan 3 kali ulangan. Data yang diperoleh dianalisis dengan menggunakan analisis varians. Hasil analisis varians yang menunjukkan beda nyata, diuji lebih lanjut dengan menggunakan uji LSD (Least Significant Difference). Parameter yang diamati dalam penelitian ini adalah intensitas serangan jamur pewarna (blue stain) pada kayu setelah dilakukan pengawetan serta kadar ektraktif kayu sebagai parameter pendukung.

Bahan pengawet diperoleh dari daun cengkeh, mindi, dan sirih yang telah dibersihkan kemudian dibuat serbuk dengan menggunakan blender. Selanjutnya serbuk dikeringanginkan dan diayak dengan ayakan ukuran 25 mesh. Serbuk diekstrak dengan menggunakan pelarut air panas dengan perbandingan antara serbuk dengan pelarut 1:5, kemudian larutan diaduk rata dan didiamkan selama 48 jam. Serbuk daun yang telah bercampur air disaring sehingga diperoleh larutan sebagai hasil ekstraksi yang digunakan sebagai bahan pengawet. Selanjutnya dibuat larutan bahan pengawet dengan konsentrasi $10 \%$ dengan pelarut air untuk mengawetkan kayu sengon dan surian.

Pengujian kadar ekstraktif kayu sengon dan surian dilakukan dengan pembuatan serbuk kayu sebanyak 2 gram kemudian dimasukkan dalam kertas saring. Ekstraksi dilakukan dengan pelarut alkohol-benzena dengan perbandingan antara alkohol dan benzena 1:2 selama 6 kali pencucian, dengan menggunakan alat soxhlet dan dilakukan pemanasan.

Untuk pembuatan contoh uji, dilakukan pemotongan log kayu sengon dan surian yang masih dalam kondisi basah atau segar menjadi papan, kemudian dibuat contoh uji dengan ukuran 20 x 10 x 1 cm (panjang x lebar x tebal). Selanjutnya contoh uji direndam dalam larutan bahan pengawet selama 3 hari. Setelah itu contoh uji dikeluarkan dari dalam rendaman dan diletakkan pada tempat yang lembab untuk pengumpanan secara alami terhadap jamur pewarna selama 1 bulan. Setelah pengumpanan, dilakukan perhitungan intensitas serangan jamur pewarna (\%) dengan menghitung luas kedua permukaan tangensial contoh uji yang terserang jamur pewarna, kemudian dibandingkan dengan total luas permukaan tangensial contoh uji. 


\section{HASIL DAN PEMBAHASAN}

Hasil analisis varians intensitas serangan jamur pewarna menunjukkan bahwa jenis fungisida nabati dan jenis kayu yang diawetkan serta interaksi antara kedua faktor tersebut berpengaruh sangat nyata terhadap intensitas serangan jamur pewarna. Selanjutnya hasil uji LSD (Least Significant Difference) pengaruh jenis fungisida nabati dan jenis kayu yang diawetkan terhadap intensitas serangan jamur pewarna, disajikan pada Tabel 1.

Tabel 1. Uji LSD pengaruh jenis fungisida nabati dan jenis kayu yang diawetkan

terhadap intensitas serangan jamur pewarna

\begin{tabular}{|c|c|c|c|}
\hline \multirow{2}{*}{$\begin{array}{l}\text { Jenis Fungisida } \\
\text { Nabati }\end{array}$} & \multicolumn{2}{|c|}{$\begin{array}{c}\text { Intensitas Serangan Jamur Pewarna (\%) } \\
\text { Jenis Kayu yang Diawetkan }\end{array}$} & \multirow[t]{2}{*}{ Rata-Rata } \\
\hline & Sengon & Surian & \\
\hline Kontrol & $84,570 \mathrm{a}$ & $27,668 \mathrm{~b}$ & $50,119 \mathrm{f}$ \\
\hline Cengkeh & $26,393 \mathrm{~b}$ & $2,428 \mathrm{c}$ & $14,411 \mathrm{~g}$ \\
\hline Mindi & $20,131 \mathrm{~b}$ & $0,918 \mathrm{c}$ & $10,525 \mathrm{~g}$ \\
\hline Sirih & $26,477 \mathrm{~b}$ & $1,595 \mathrm{c}$ & $14,036 \mathrm{~g}$ \\
\hline Rata-Rata & $39,393 \mathrm{~d}$ & $8,152 \mathrm{e}$ & \\
\hline
\end{tabular}

Keterangan: Angka rata-rata yang diikuti huruf yang sama, menunjukkan tidak berbeda nyata pada taraf uji $1 \%$

Hasil uji LSD pada Tabel 1 menunjukkan bahwa kayu sengon dan surian yang diawetkan dengan ekstrak daun cengkeh, mindi dan sirih menghasilkan intensitas serangan jamur pewarna yang lebih rendah dan berbeda sangat nyata dibandingkan dengan kayu yang tidak diawetkan (kontrol). Hal ini berarti ketiga jenis fungisida nabati tersebut dapat melindungi kayu terhadap serangan jamur pewarna. Intensitas serangan jamur pewarna terendah dihasilkan pada kayu surian yang diawetkan dengan ekstrak daun mindi, yaitu sebesar 0,918\%, meskipun hasil tersebut tidak berbeda nyata dengan kayu surian yang diawetkan dengan ekstrak daun cengkeh dan sirih. Intensitas serangan jamur pewarna pada kayu surian yang diawetkan dengan ekstrak daun mindi telah mendekati 0\% (sama sekali tidak terserang jamur), sehingga efektivitas daun mindi sebagai bahan pengawet untuk kayu surian tergolong tinggi, yaitu mampu mencegah serangan jamur pewarna, tidak sekedar mengurangi serangan. Menurut Manan dan Mugiastuti (2019), dalam daun mindi terkandung senyawa yang bersifat bioaktif yaitu alkaloid, tanin, saponin, fenolik, triterpenoid dan flavonoid. Berdasarkan kandungan senyawa kimia dalam daun mindi tersebut maka jenis daun ini memiliki potensi untuk dipergunakan sebagai fungisida nabati untuk mencegah serangan jamur pewarna kayu. Intensitas serangan jamur pewarna pada kayu sengon dan surian yang diawetkan dengan berbagai jenis fungisida nabati, disajikan dalam bentuk grafik pada Gambar 1. 


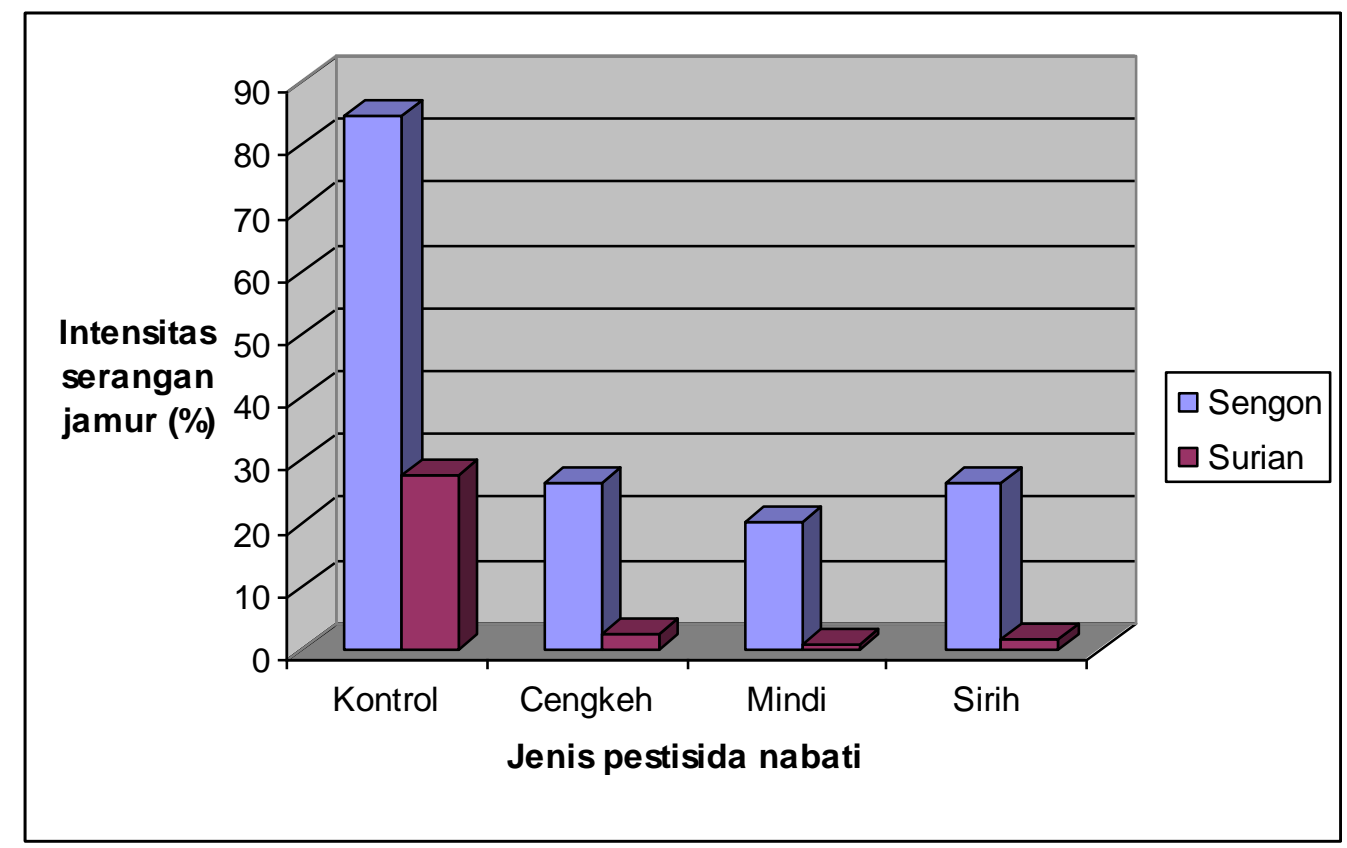

Gambar 1. Intensitas serangan jamur pewarna pada kayu sengon dan surian yang diawetkan dengan berbagai jenis fungisida nabati

Jenis-jenis bahan aktif yang terkandung dalam daun cengkeh (Syzygium aromaticum), mindi (Melia azedarach), dan sirih (Piper betle) dari berbagai sumber, yang berpotensi sebagai fungisida nabati, disajikan dalam Tabel 2 sebagai berikut :

Tabel 2. Jenis-jenis bahan aktif yang terkandung dalam ekstrak daun cengkeh, mindi dan sirih

\begin{tabular}{|c|c|}
\hline Jenis Ekstrak Daun & Bahan Aktif \\
\hline Cengkeh (Syzygium aromaticum) & $\begin{array}{l}\text { Eugenol, minyak atsiri. flavonoid, triterpenoid, } \\
\text { fenolat, tanin, eucalyptol, kariofilen, cardinol, } \\
\text { limonene }\end{array}$ \\
\hline Mindi (Melia azedarach) & $\begin{array}{l}\text { Azadirahtin, meliantin, meliantriol, paraisin, salanin, } \\
\text { nimbin, alkaloid, tannin, saponin, fenolik, } \\
\text { triterpenoid, flavonoid }\end{array}$ \\
\hline Sirih (Piper betle) & $\begin{array}{l}\text { Fenol (kavikol dan kavibetol), alilpirokavikol, sinol, } \\
\text { kadinen, estragol, terpen, seskuiterpen, fenil propane, } \\
\text { tanin,eugenol, minyak atsiri }\end{array}$ \\
\hline
\end{tabular}

Sumber: Tjitrosoepomo (1994), Prakash dan Rao (1997), Kardinan (1999), Pratiwi dan Muderawan (2016), Manan dan Mugiastuti (2019), Suhendra dan Sogandi (2019)

Ditinjau dari pengaruh jenis fungisida nabati terhadap intensitas serangan jamur pewarna menunjukkan bahwa ekstrak daun mindi menghasilkan rata-rata intensitas serangan jamur pewarna yang terendah, yaitu sebesar 10,525\%, meskipun hasil tersebut tidak berbeda nyata dengan ekstrak daun cengkeh dan sirih. Dalam ekstrak daun mindi terkandung bahan aktif azadirachtin yang tidak dimiliki oleh ekstrak daun cengkeh dan sirih, seperti yang disajikan pada Tabel 2. Bahan aktif azadirachtin tersebut diduga lebih bersifat racun terhadap jamur pewarna dibandingkan eugenol yang terdapat dalam ekstrak daun cengkeh dan daun sirih. Hasil penelitian Montesqrit et al. (2019) menunjukkan bahwa daun mindi mengandung senyawa volatil spesifik yang bersifat fungisida. Menurut Suhendra dan Sogandi (2019), daun 
cengkeh mengandung senyawa kimia berupa flavonoid, triterpenoid, fenolat dan tanin yang merupakan senyawa yang bersifat anti bakteri. Selanjutnya hasil penelitian Pratiwi dan Muderawan (2016) menunjukkan bahwa dalam daun sirih terkandung senyawa eugenol yang merupakan senyawa fenolik yang bersifat anti bakteri. Dengan demikian ketiga jenis fungisida tersebut, yaitu daun cengkeh, mindi dan sirih memiliki potensi untuk dipergunakan sebagai bahan pengawet kayu untuk mengatasi serangan jamur pewarna kayu.

Hasil pengamatan terhadap sifat fisik atau kenampakan kayu setelah diawetkan menunjukkan bahwa ektrak daun cengkeh sedikit mengubah warna asli kayu, ekstrak daun sirih cukup banyak mengubah warna asli kayu, sedangkan ekstrak daun mindi sama sekali tidak mengubah warna asli kayu. Untuk mengawetkan jenis-jenis kayu berwarna muda seperti kayu sengon, ekstrak daun mindi lebih tepat untuk digunakan karena tidak mengubah warna asli kayu tersebut, sehingga kayu masih dapat difinishing dengan baik. Kandungan minyak atsiri yang terdapat dalam daun cengkeh dan sirih (Tabel 2) dapat menjadi penyebab timbulnya pewarnaan pada kayu yang diawetkan, sehingga kayu yang berwarna muda atau terang menjadi lebih gelap setelah diawetkan.

Ditinjau dari pengaruh jenis kayu terhadap intensitas serangan jamur pewarna menunjukkan bahwa intensitas serangan jamur pewarna pada kayu surian lebih rendah dari pada kayu sengon, yaitu masing-masing sebesar 8,152\% pada kayu surian dan 39,393\% pada kayu sengon. Ini menunjukkan kayu surian lebih tahan terhadap serangan jamur pewarna, meskipun jenis kayu ini memiliki kelas awet yang sama dengan kayu sengon, yaitu tergolong kelas awet IV/V. Hal ini dapat disebabkan perbedaan kandungan zat ekstraktif yang terdapat dalam kedua jenis kayu tersebut. Hasil pengujian rata-rata kadar ekstraktif kayu sengon (Paraserinthes falcataria) dan surian (Toona sureni) disajikan pada Tabel 3.

Tabel 3. Kadar ekstraktif kayu sengon dan surian larut dalam alkohol-benzena (\%)

\begin{tabular}{lc}
\hline \multicolumn{1}{c}{ Jenis Kayu } & Rata-Rata Kadar Ekstraktif (\%) \\
\hline Sengon (Paraserianthes falcataria) & 10,31 \\
Surian (Toona sureni) & 13,07 \\
\hline
\end{tabular}

Hasil pengujian kadar ekstraktif pada Tabel 3 menunjukkan bahwa kayu surian memiliki kadar ekstraktif yang lebih tinggi dari pada kayu sengon, yaitu pada kayu surian 13,07\% dan pada kayu sengon 10,31\%. Menurut Nicholas (1987) dan Schwarze et al. (2000), faktor utama yang menentukan ketahanan atau keawetan alami kayu adalah adanya zat ekstraktif yang mampu bersifat sebagai fungisida atau insektisida alami, sehingga terdapat jenis-jenis kayu tertentu yang tahan terhadap serangan organisme perusak kayu tertentu. Dengan demikian kandungan atau kadar ektraktif yang berbeda pada kayu sengon dan surian menyebabkan perbedaan ketahanan kedua jenis kayu tersebut terhadap jamur pewarna. 


\section{KESIMPULAN}

1. Interaksi antara jenis fungisida nabati dan jenis kayu berpengaruh sangat nyata terhadap intensitas serangan jamur pewarna. Intensitas serangan jamur pewarna terendah dihasilkan pada kayu surian yang diawetkan dengan ekstrak daun mindi, yaitu sebesar 0,918\%.

2. Ekstrak daun cengkeh, mindi dan sirih efektif digunakan untuk mengurangi serangan jamur pewarna pada kayu sengon dan surian, sehingga dapat digunakan sebagai bahan pengawet kayu alternatif yang murah dan ramah lingkungan.

3. Kayu surian lebih tahan terhadap jamur pewarna dibandingkan dengan kayu sengon karena kayu surian memiliki kandungan zat ekstraktif yang lebih tinggi dibandingkan kayu sengon.

4. Untuk mengawetkan jenis-jenis kayu yang berwarna muda seperti kayu sengon, lebih tepat digunakan ekstrak daun mindi sebagai bahan pengawet yang tidak mengubah warna asli kayu setelah diawetkan.

\section{DAFTAR PUSTAKA}

Fengel, D. dan G. Wegener. 1995. Kayu: Kimia, Ultrastruktur, Reaksi-Reaksi. Gadjah Mada University Press. Yogyakarta.

Hembing, W. 1992. Tanaman Berkhasiat Obat di Indonesia. Pustaka Kartini. Jakarta.

Hunt, G.M. dan G.A. Garratt. 1986. Pengawetan Kayu. CV Akademika Pressindo. Jakarta.

Kardinan, A. 1999. Pestisida Nabati, Ramuan dan Aplikasinya. PT Penebar Swadaya. Jakarta.

Kusumo, H.W. dan Wiriawan, S.A. 1994. Tanaman Berkhasiat Obat. Jilid I. Pustaka Kartini. Jakarta.

Manan, A. dan E. Mugiastuti. 2019. Pengaruh Ekstrak Daun Mindi (Melia azedarach) terhadap Penekanan Peletakan dan Penetasan Telur Ulat Hati Kubis (Crocidolomia pavonana F.). Jurnal Agrotek Vol. 6, No. 2, Agustus 2019.

Martawijaya, A. dan Barly. 1991. Petunjuk Teknis Pengawetan Kayu Bangunan Perumahan dan Gedung. Badan Penelitian dan Pengembangan Kehutanan. Departemen Kehutanan. Jakarta.

Montesqrit, Harnentis dan Sri Yana. 2019. Pengaruh Penambahan Daun Mindi (Melia azedarach) terhadap Kualitas Jagung Pipilan Selama Penyimpanan. Jurnal Pastura Vol. 8, No. 2, Tahun 2019.

Novizan. 2002. Membuat dan Memanfaatkan Pestisida Ramah Lingkungan. Agro Media Pustaka. Jakarta.

Nicholas, D.D. 1987. Kemunduran (Deteriorasi) Kayu dan Pencegahannya Dengan PerlakuanPerlakuan Pengawetan. Jilid I. Airlangga University Press. Surabaya.

Prakash, A. and J. Rao. 1997. Botanical Pesticides in Agriculture. CRC Press. Inc. Lewis Publishers, Boca Raton, Florida.

Pratiwi, N.P.R.K. dan I. W. Muderawan. 2016. Analisis Kandungan Kimia Ekstrak Daun Sirih Hijau (Piper betle) dengan GC-MS. Prosiding Seminar Nasional MIPA Universitas Pendidikan Ganesha. Singaraja.Bali.

Schwarze, F.W.M.R., J. Engels, and C. Mattheck. 2000. Fungal Strategies of Wood Decay in Trees. Springer. Verlagh Berlin Heidelberg. Germany. 
Sitepu, D. 1996. Prospek Pestisida Nabati di Indonesia. Balai Penelitian Tanaman Rempah dan Obat. Bogor.

Suhendra, U. dan Sogandi. 2019. Identifikasi Senyawa Aktif Ekstrak Daun Cengkeh (Syzygium aromaticum) Sebagai Inhibitor Streptococcus mutans. Jurnal Biologi Al. Kauniyah Vol. 12, No. 2, Tahun 2019.

Tambunan, D. dan D. Nandika. 1989. Deteriorasi Kayu Oleh Faktor Biologis. Pusat Antar Universitas Bioteknologi. Institut Pertanian Bogor. Bogor.

Tjitrosoepomo, G. 1994. Taksonomi Tumbuhan Obat-Obatan. Gadjah Mada University Press. Yogyakarta. 